\title{
MODELING OF CYCLIC GEARSHIFTS IN AUTOMATIC TRANSMISSIONS FOR VEHICLES
}

\author{
Konstantin Salamandra, Leonid Tyves \\ Mechanical Engineering Research Institute of the Russian Academy of Sciences, Russia \\ ksalamandra@yandex.ru, 1-tyves@hovrino.net
}

\begin{abstract}
One of the most effective ways to improve the efficiency of vehicles is to reduce the engine operating range by increasing the number of overall gear ratios in automatic transmissions. In this case, the step between the gear ratios decreases. It leads to decreasing the difference between program values of speeds, at which the gearshifts occur. It is one of the reasons for cyclic gearshifts (oscillating shifts) between two adjacent gear ratios, which leads to passenger discomfort, reduced transmission resource and increased loads on the transmission elements. High-frequency oscillating gearshifts can occur in the case of self-oscillation of the output shaft of the gearbox caused by gearshifts. With significant amplitude of speed fluctuations, the control system will shift to the previous gear. Low-frequency oscillating gearshifts are associated with the inability to maintain the selected speed of the vehicle in the zone, where its values are close to the values of speeds shifting to the adjacent gear ratios. Such wrong gearshifts occur due to frequent changes in external traffic conditions, for example, on hilly or winding roads. The article is devoted to the analysis of these dynamic processes and their simulation. The dynamic model of the automatic transmission is considered. The model reflects the most essential properties of the transmission: inertia of the transmission elements, stiffness and damping, program values of the gearbox output shaft speeds, at which gearshifts occur. The results of dynamics simulation of simplified transmission models with automatic transmission are presented. The dynamic model can be used to develop intelligent control systems for automatic transmissions, for simulation of various driving conditions of the vehicle and to calibrate the engine and transmission.
\end{abstract}

Keywords: gearshift, automatic transmission, oscillating shifts, dynamics, gearbox.

\section{Introduction}

The main way to reduce fuel consumption of the vehicles is to ensure the operation of the engine in a narrow range of speeds, characterized by the best efficiency. Reducing the range of engine operating speeds leads to an increase in the number of gears in automatic transmissions [1] and to the convergence of the shifting speeds of neighbouring gears [2-5]. The proximity of shifting speeds of neighbouring gears can cause low and high frequency oscillating shifts [2;5].

Low-frequency oscillating shifts are observed, when the vehicle moves uniformly at speeds, which are close to shifting speeds to neighbouring gears with periodic changes of external conditions. For example, at driving on the road with frequent changes of up and downhill: when moving uphill the low gear is switching on and the high gear engages at downhill moving. The same can occur on winding roads: low gear is switching on before the turn and the high gear is engaging after the turn. The problems of diagnosing such cyclic shifting, experimental data and ways to reduce the probability of their appearance by taking into account additional parameters that indirectly indicate oscillating shifts were considered in [6-8].

High-frequency oscillating shifts are associated with a short duration of the gearshift process in the automatic transmissions. Currently, due to the use of modern friction materials, high-speed hydraulic drives and the wide possibilities of control systems, the period of gearshift is in the range of $0.2-0.5 \mathrm{sec}[3 ; 5 ; 9]$. The shifting process acquires the properties of the impact interaction of the transmission elements at such small values of time. That is exciting the oscillations of the output shaft of the gearbox, which rotation speed is read by the sensor of the control system. The inertial torque caused by a sudden speed change of the transmission elements during the shift significantly exceeds the engine torque and the reduced inertial torques of the motion resistance forces. The amplitude of the rotation speed of the gearbox output shaft at a small damping can be very significant and will cause a reverse shifting to the previous gear and lead to oscillating shifts, which can increase dynamic loads on the elements of the vehicle's transmission.

The purpose of this study is dynamic analysis of the automatic transmission model based on the numerical simulation of the motion modes with oscillating shifts of the gears at different frequencies and determination of the boundaries of their existence in the parameters of the system. 


\section{Methods of the research}

Methods for investigating the dynamic processes of gearshifts in automatic transmission systems are based mainly on the differential principle of theoretical mechanics, in which the process is divided into stages and differential equations of dynamics are compiled at each stage [2-5; 9-11]. Because of the shifting duration is close to zero, it seems expedient to use the integral principle based on the angular momentum conservation law $[12 ; 13]$.

The dynamic model of the two-speed automatic transmission is presented in Figure 1.

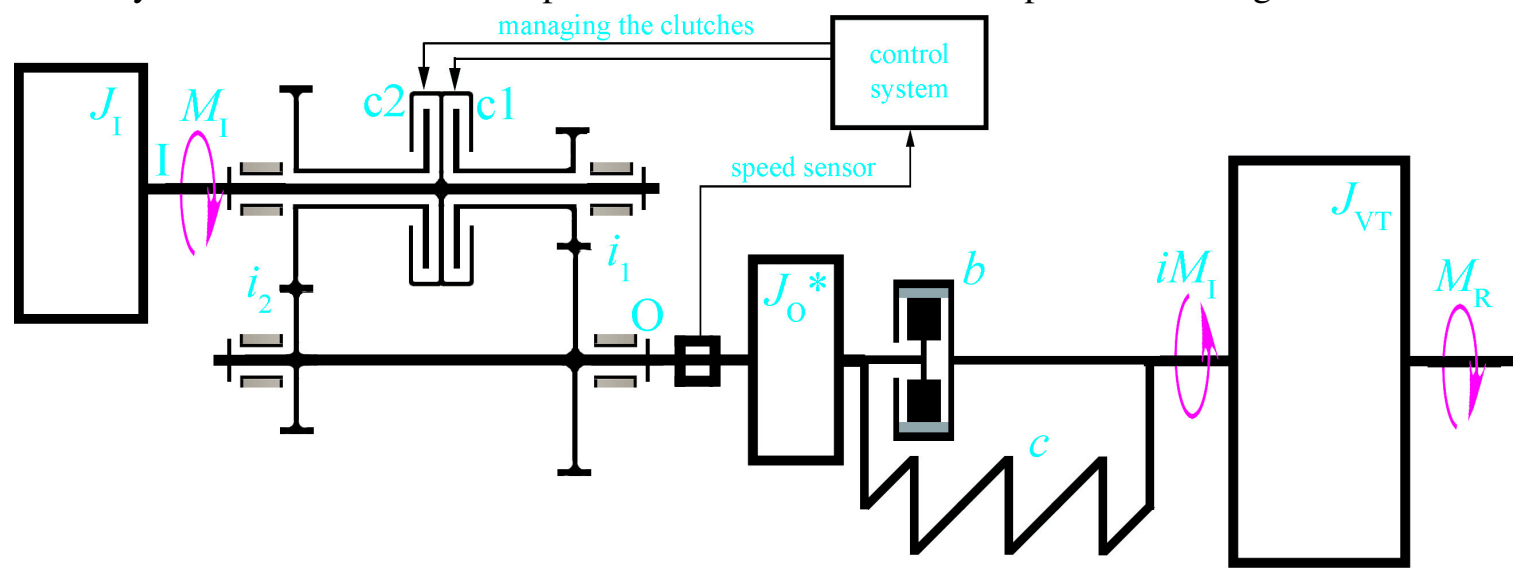

Fig. 1. Two-speed automatic transmission dynamic model

The inertial element $J_{I}$ on the input shaft I of the transmission represents the moments of inertia of the moving members of the engine reduced to the input shaft. The element $J_{O}{ }^{*}$ on the output shaft $O$ represents the moment of inertia of the output shaft of the gearbox and the inertia moments of sequential transmission parts to the member with maximum elasticity. Element $J_{V T}$ is the reduced moments of inertia of the transmission members after the member with maximum elasticity is including the body of the vehicle. $J_{O}{ }^{*}$ and $J_{V T}$ are connected by an elastic link with stiffness coefficients $c$ and damping $b$. The gearshift map from the first gear to the second is stored in the control system as fixed speed values. Information about the speed of rotation of the element $J_{O}{ }^{*}$ comes from the speed sensor to the control system and is used to manage the clutches $\mathrm{c} 1$ and $\mathrm{c} 2$, which switch-on and switch-off the gears with the gear ratios $i_{1}$ and $i_{2}$, respectively. $M_{I}$ and $M_{R}$ - the input shaft torque of the automatic transmission and the torque of resistance force, respectively.

The experience of applying the integral principle in solving dynamic analysis problems of the gearshifting process in the automatic transmission [13] allows us proceed to a simplified impact model.

A simplified model of a two-speed transmission with elastic and dissipative elements is shown in Figure 2.

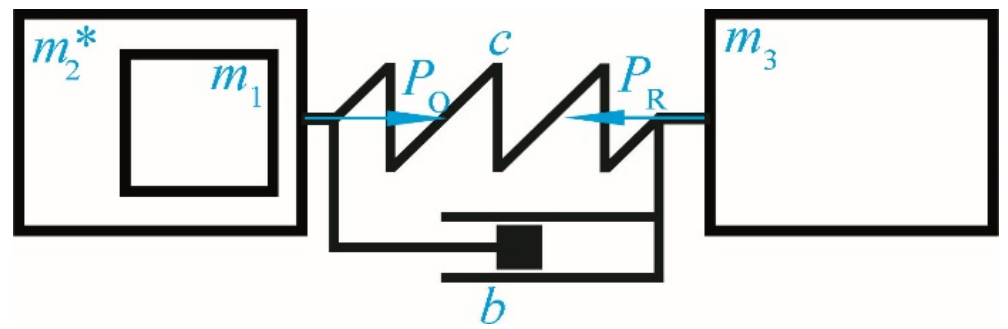

Fig. 2. Simplified gearshifting model

The rotation elements in Figure 1 are replaced with the elements of rectilinear motion in Figure 2. There are the following correspondences between the two dynamic models examined: $m_{1} \sim J_{1}, m_{2}{ }^{*} \sim J_{0}{ }^{*}$, $m_{3} \sim J_{V T}, i M_{\Gamma} \sim P_{O}, M_{R} \sim P_{R}$. Elements with the stiffness coefficient $c$ and damping $b$ link masses $m_{2}{ }^{*}$ (frame in Figure 2) and $m_{3}$. The process of gearshift in the model is reduced to a "soft" separation of the mass $m_{1}$ from one side of the frame $m_{2}{ }^{*}$ and the subsequent shock connection with a zero-speed recovery coefficient with its other frame side. Thus, there is a "violent" transfer of the mass $m_{1}$ from one side of the frame $m_{2}{ }^{*}$ to the other, which reflects the effect of a quick coupling of the transmission 
inertial elements reduced to the clutch plates from the input and output shafts. In the intervals between the gearshifts the masses $m_{1}$ and $m_{2}{ }^{*}$ represent a single mass $\left(m_{1}+m_{2}{ }^{*}\right)$.

The velocity $\dot{x}_{2}$ of the mass $m_{2}{ }^{*}$ (analogue of the "output shaft of the gearbox") is read by the speed sensor. We introduce the values of the velocities $\dot{x}_{2}$ given in the gearshift program, when the shifts occur: $\dot{x}_{2}{ }^{(12)}-$ from the first to the second gear and $\dot{x}_{2}{ }^{(21)}-$ from the second to the first gear (in the parameters of the combined mass $\left(m_{1}+m_{2}{ }^{*}\right)$ the subscript is not specified). In order to shift from the first gear to the second it is necessary that $\ddot{x}>0$, and $\ddot{x}<0$, when shifting from the second to the first gear.

The effect of the impact at gearshifting in the automatic transmission is explained by the rapid change in the kinematic relationships determined by the gear ratios. The greater the difference between the gear ratios, the larger the magnitude of the impact impulse. In order to take this effect into account in the simplified model we introduce as parameters the fixed values of mass velocities $m_{1}$ before the shift: $\dot{x}_{1}^{(12)}=\rho_{12} \dot{x}^{(12)}$ when shifting from the first gear to the second (the impact to the right frame side, see Figure 2); $\dot{x}_{1}^{(21)}=\rho_{21} \dot{x}^{(21)}$ when shifting from the second gear to the first (impact to the left side). Here $\rho_{12}$ and $\rho_{21}$ are constant parameters, $\rho_{21}>1$ and $\rho_{21}<1$. In this case, when the $m_{1}$ impacts to the right side of the frame, the mass velocity $\left(m_{1}+m_{2}{ }^{*}\right)$ will increase. And when it impacts to the left side, the mass velocity $\left(m_{1}+m_{2}{ }^{*}\right)$ decreases accordingly to [13]. By introducing the coefficients $\rho_{12}$ and $\rho_{21}$ in a simplified model the impact interaction of the transmission elements during the gearshift is actually replaced by an external impulse action. The velocity of the mass $m_{2}{ }^{*}$ before the shift, for example, from the first gear to the second $\dot{x}^{(12)}$ and the velocity of the mass $m_{1}$ at this moment $\rho_{12} \dot{x}^{(12)}$. Taking into account the impulse action introduced, the momentum conservation law allows to determine the mass velocity $\left(m_{1}+m_{2}{ }^{*}\right)$ after the shift $\dot{x}=\dot{x}^{(12)}\left(m_{1} \rho_{12+} m_{2}{ }^{*}\right) /\left(m_{1}+m_{2}{ }^{*}\right)$. In this case the velocity of the combined mass after the gearshift is increased.

The transformation of the model in Figure 2 in the intervals between the "gearshifting" is described by the system of two linear differential equations:

$$
\begin{aligned}
& \left(m_{1}+m_{2}^{*}\right) \ddot{x}+b\left(\dot{x}-\dot{x}_{3}\right)+c\left(x-x_{3}\right)=P_{O} \\
& m_{3} \ddot{x}_{3}+b\left(\dot{x}_{3}-\dot{x}\right)+c\left(x_{3}-x\right)=-P_{R},
\end{aligned}
$$

where $x$-movement of the mass $\left(m_{1}+m_{2}{ }^{*}\right)$;

$x_{3}$ - movement of the mass $m_{3}$.

The dynamic model characterized by the system (1) has been considered in the scientific and technical literature since the beginning of the $20^{\text {th }}$ century in all books on the theory of oscillations $[14 ; 15]$, in research works [16;17], as part of the vibro-impact system [18], as well as in the study of mechanical systems with discontinuous nonlinearities [19].

Frequencies of free oscillations of the model at the absence of damping:

$$
k_{1}=0 ; k_{2}=\sqrt{c\left(m_{1}+m_{2}^{*}+m_{3}\right) /\left(m_{1}+m_{2}^{*}\right) m_{3}} \text {. }
$$

The frequency of damped oscillations is

$$
k_{2}^{*}=\sqrt{k_{2}^{2}-h^{2}},
$$

where

$$
h=\frac{b\left(m_{1}+m_{2}^{*}+m_{3}\right)}{2\left(m_{1}+m_{2}^{*}\right) m_{3}} .
$$

The values of the inertial elements, stiffness and damping coefficients do not change from gear to gear and consequently the frequency $k_{2}{ }^{*}$ remains constant in the considered simplified model shown in Figure 2. The frequency $k_{2}{ }^{*}$ in each gear is different in the automatic transmission model shown in Figure 1. This is because the moments of inertia of the driver members (engine, etc.) reduced to the output shaft of the gearbox depend on the implementing gear ratio. The accepted assumption is justified by the fact that the magnitudes of gear ratios of the neighbouring gears are close as noted above. 


\section{Movement of the model between gearshifts}

The motion of the model between the gearshifts is the oscillations of the masses $\left(m_{1}+m_{2}{ }^{*}\right)$ and $m_{3}$ relatively to the centre of mass, which is moving under the action of the driving and resistance forces $P_{O}=$ const $\neq 0, P_{R}=$ const $\neq 0$. The motion of the centre of mass of the model is a portable movement of the model. The relative mass motion $\left(m_{1}+m_{2}{ }^{*}\right)$ and $m_{3}$ are synchronous oscillations of these masses in antiphase, the values of the vibration amplitudes being inversely proportional to the masses [15]. The general solution of the equations (1) obtained the form:

$$
\begin{aligned}
& x=A e^{-h t} \sin \left(k_{2}^{*} t+\beta\right)+C_{1}+C_{2} t+a t^{2} / 2 \\
& x_{3}=\mu A e^{-h t} \sin \left(k_{2}^{*} t+\beta\right)+C_{1}+C_{2} t+a t^{2} / 2,
\end{aligned}
$$

where $\quad \mu=A_{3} / A=-\left[\left(m_{1}+m_{2}^{*}\right) / m_{3}\right]$;

$$
a=\left(P_{O}-P_{R}\right) /\left(m_{1}+m_{2}^{*}+m_{3}\right)-\text { acceleration. }
$$

The constants $A, \beta, C_{1}$ and $C_{2}$ are defined by initial conditions of the system - through the initial positions and mass velocities of the model. In (2) the parameters $C_{1}, C_{2}$ and $a$ are the characteristics of the centre of mass motion of the model (the portable motion). The parameters $A$ and $\beta$ are the characteristics of the relative motion. The initial position of the centre of mass of the model $C_{1}$ is assumed to be zero.

By differentiating equations (2) we obtain the general form of the equations of mass velocities at the $i$ gear $(i=1,2)$ between the shifts:

$$
\begin{aligned}
& \dot{x}^{(i)}=A^{(i)} e^{-h t}\left(k_{2}^{*} \cos \left(k_{2} t+\beta^{(i)}\right)-h \sin \left(k_{2}^{*} t+\beta^{(i)}\right)\right)+C_{2}^{(i)}+a^{(i)} t, \\
& \dot{x}_{3}^{(i)}=\mu A^{(i)} e^{-h t}\left(k_{2}^{*} \cos \left(k_{2}^{*} t+\beta^{(i)}\right)-h \sin \left(k_{2}^{*} t+\beta^{(i)}\right)\right)+C_{2}^{(i)}+a^{(i)} t .
\end{aligned}
$$

The portable velocity $C_{2}{ }^{(i)}$ is the initial velocity of the centre of mass of the model in the $i$ gear. By substituting

$$
\sin \alpha=h / \sqrt{h^{2}+k_{2}^{* 2}} \text { and } \cos \alpha=k_{2}^{*} / \sqrt{h^{2}+k_{2}^{* 2}}
$$

the expressions for the mass velocities are transformed to the next form:

$$
\begin{aligned}
& \dot{x}^{(i)}=A^{(i)} e^{-h t} \sqrt{h^{2}+k_{2}^{* 2}} \cos \left(k_{2}^{*} t+\beta^{(i)}+\alpha\right)+C_{2}^{(i)}+a^{(i)} t \\
& \dot{x}_{3}^{(i)}=\mu A^{(i)} e^{-h t} \sqrt{h^{2}+k_{2}^{* 2}} \cos \left(k_{2}^{*} t+\beta^{(i)}+\alpha\right)+C_{2}^{(i)}+a^{(i)} t .
\end{aligned}
$$

According to the above description the simplified impact transmission model is an impulse autooscillating system. And its modes of motion are determined by the gearshift velocities. An upshift from the first gear to the second at a given value of the gearshifting velocity will occur, when $\dot{x}^{(1)}=\dot{x}^{(12)}$ and $\dot{x}^{(1)}>0$, also downshift will occur, when $\dot{x}^{(2)}=\dot{x}^{(21)}$ and $\ddot{x}^{(2)}<0$.

In accordance with the first equation of the system (3) for a given value of $\dot{x}^{(12)}$ the upshift from the first to the second gear is possible for the following parameter relations:

$$
A^{(1)} e^{-h t} \sqrt{h^{2}+k_{2}^{* 2}}>\dot{x}^{(12)}-C_{2}^{(1)}-a^{(1)} t .
$$

The relation

$$
A^{(2)} e^{-h t} \sqrt{h^{2}+k_{2}^{* 2}}>C_{2}^{(2)}-\dot{x}^{(21)}-a^{(2)} t
$$

determines the possibility of downshift.

The various transient modes of dynamic model motion are possible depending on the values of the parameters and the initial conditions. For example, at large difference $\dot{x}^{(12)}-\dot{x}^{(21)}$ the velocity oscillation amplitude excited at gearshifts will not be sufficient to reverse gearshift and the oscillations will be damped. Decreasing in the specified velocities difference is the above-mentioned tendency of increasing the number of gears in automatic transmissions. 
The position functions (2) and the velocity function $\dot{x}_{3}$ are continuous and the velocity function $\dot{x}$ continuous only on time intervals between gearshifts, where its magnitude is abruptly changing. This is an attribute of the nonlinearity of the system under consideration. Then the stitching method is applicable for solving the dynamics problems of the system.

The conditions for stitching the coordinates and velocities of the model at shifting from the first gear to the second are:

$$
\begin{gathered}
x^{(2)}(0)=x^{(1)}\left(t_{\kappa}^{(1)}\right) ; x_{3}^{(2)}(0)=x_{3}^{(1)}\left(t_{\kappa}^{(1)}\right) \\
\dot{x}^{(2)}(0)=\frac{\left(m_{1} \rho_{12}+m_{2}^{*}\right) \dot{x}^{(12)}}{m_{1}+m_{2}^{*}} ; \dot{x}_{3}^{(2)}(0)=\dot{x}_{3}^{(1)}\left(t_{\kappa}^{(1)}\right),
\end{gathered}
$$

where $t_{k}^{(1)}-$ moment of time when $\dot{x}^{(1)=} \dot{x}^{(12)}$ and gearshift occurs from the first to the second gear.

The constants $A^{(2)}, \beta^{(2)}, C_{1}^{(2)}$ and $C_{2}^{(2)}$ are determined by substituting equations (2) and (3) into (4). The motion of the model on the second gear described by equations (2) and (3) ends at the time $t_{k}^{(2)}$ when conditions $\dot{x}^{(2)}\left(t_{k}^{(2)}\right)=\dot{x}^{(21)}$ and $\dot{x}^{(2)}\left(t_{k}^{(2)}\right)<0$ are met. This is an important point for solving the problem of the existence of oscillating shifts both high-frequency, depending mainly on the characteristics of the relative components of the motion, and low-frequency ones, determined by the characteristics of the portable movement model.

Let us denote the phase of the oscillations of the mass $\left(m_{1}+m_{2}{ }^{*}\right)$ at the time $t_{k}^{(2)}$ as $\beta_{k}^{(2)}=k_{2}{ }^{*} t_{k}^{(2)}+$ $+\beta^{(2)}$, the stitching conditions, when shifting from the second to the first gear will be:

$$
\begin{gathered}
A^{(2)} e^{-h t_{\kappa}^{(2)}} \sin \beta_{\kappa}^{(2)}+C_{2}^{(2)} t_{\kappa}^{(2)}+a^{(2)}\left(t_{\kappa}^{(2)}\right)^{2} / 2=A^{(1)} \sin \beta^{(1)}+C_{1}^{(1)} \\
\mu A^{(2)} e^{-h t_{\kappa}^{(2)}} \sin \beta_{\kappa}^{(2)}+C_{2}^{(2)} t_{\kappa}^{(2)}+a^{(2)}\left(t_{\kappa}^{(2)}\right)^{2} / 2=\mu A^{(1)} \sin \beta^{(1)}+C_{1}^{(1)} \\
\frac{\left(m_{1} \rho_{21}+m_{2}^{*}\right) x^{(21)}}{m_{1}+m_{2}^{*}}=A^{(1)} \sqrt{h^{2}+k_{2}^{* 2}} \cos \left(\beta^{(1)}+\alpha\right)+C_{2}^{(1)} \\
\mu A^{(2)} e^{-h t_{\kappa}^{(2)}} \sqrt{h^{2}+k_{2}^{* 2}} \cos \left(\beta_{\kappa}^{(2)}+\alpha\right)+C_{2}^{(2)}+a^{(2)} t_{\kappa}^{(2)}= \\
\mu A^{(1)} \sqrt{h^{2}+k_{2}^{* 2}} \cos \left(\beta^{(1)}+\alpha\right)+C_{2}^{(1)} .
\end{gathered}
$$

Solutions of the system of equations (5) will be:

$$
\begin{gathered}
\sin \beta^{(1)}=\frac{A^{(2)}}{A^{(1)}} e^{-h t_{\kappa}^{(2)}} \sin \beta_{\kappa}^{(2)} \\
A^{(1)}=\frac{1}{k_{2}^{*}} \sqrt{\left(\dot{x}^{(1)}(0)-C_{2}^{(1)}+h A^{(2)} e^{-h t_{\kappa}^{(2)}} \sin \beta_{\kappa}^{(2)}\right)^{2}+\left(A^{(2)} k_{2}^{*} e^{-h t_{\kappa}^{(2)}} \sin \beta_{\kappa}^{(2)}\right)^{2}} \\
C_{2}^{(1)}=C_{2}^{(2)}+a^{(2)} t_{\kappa}^{(2)}+\dot{x}^{(21)} m_{1} \frac{\left(\rho_{21}-1\right)}{m_{1}+m_{2}^{*}+m_{3}} .
\end{gathered}
$$

An analytic solution of the system of equations (5) requires determination of the duration of the time interval $t_{k}^{(2)}$. The first equation of the system (3) allows to determine the time $t_{k}^{(2)}$ and the final phase $\beta_{k}^{(2)}$ of oscillations before the shift to the first gear:

$$
\beta_{\kappa}^{(2)}=k_{2}^{*} t_{\kappa}^{(2)}+\beta^{(2)}=\operatorname{acos} \frac{\dot{x}^{(21)}-C_{2}^{(2)}-a^{(2)} t_{\kappa}^{(2)}}{A^{(2)} e^{-h t_{\kappa}^{(2)}} \sqrt{h^{2}+k_{2}^{* 2}}}-\alpha .
$$

Equation (7) cannot be solved analytically. Therefore, it seems rational to perform a numerical simulation of the model motion process for various values of its parameters. 


\section{Results of numerical simulation}

Numerical simulation of oscillating gearshifts and demonstration of the system behaviour under various conditions will be shown to illustrate the dependences obtained above on the time variation graphs.

1. Low-frequency oscillating gearshifts in automatic transmission at variable acceleration. Such a process can be illustrated by the graph in Figure 3.

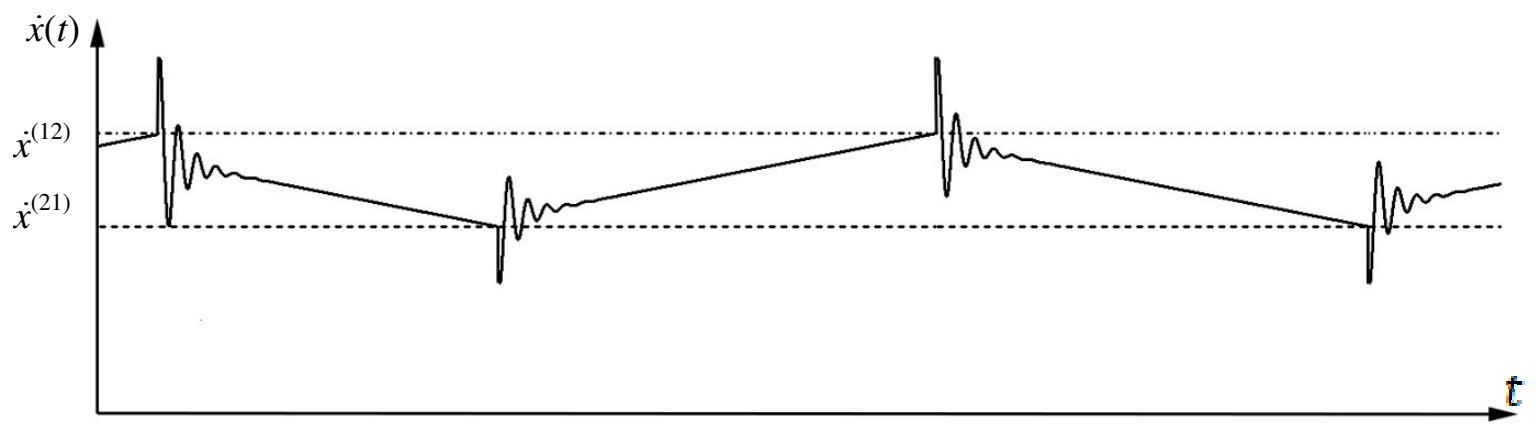

Fig. 3. Graph of low-frequency oscillating shifts in automatic transmission

The adequacy of the proposed mathematical model is characterized by the coincidence of the form of the obtained graph of the speed change of the output shaft during gearshifts with the experimental results obtained, for example, in [20].

2. High-frequency oscillating gearshifts.

We take the constants $A, \beta, C_{1}$ and $C_{2}$ equal to zero for numerical simulation at the initial stage of considering the system motion. The extreme case of high frequency oscillating gearshift is the equality of the shifting speeds of neighbouring gears, as shown in Figure 4a.

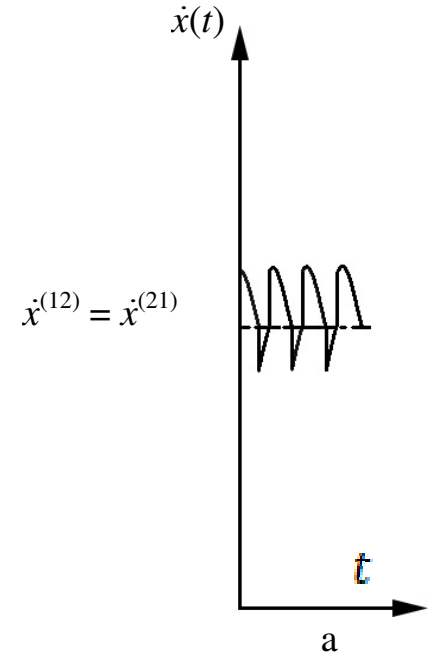

a

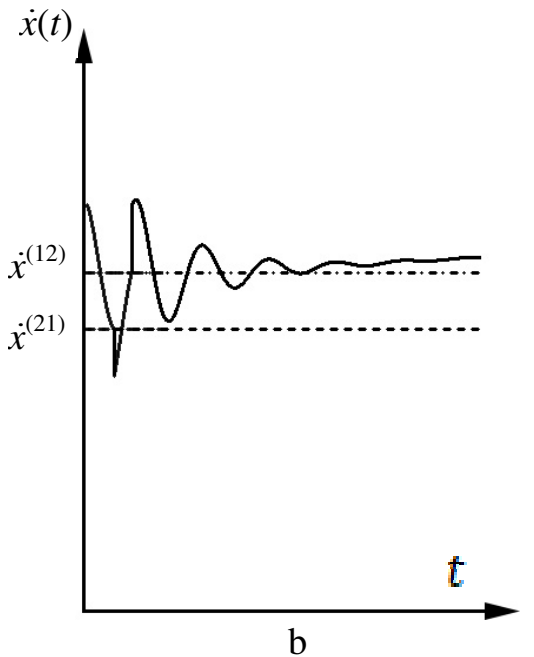

b

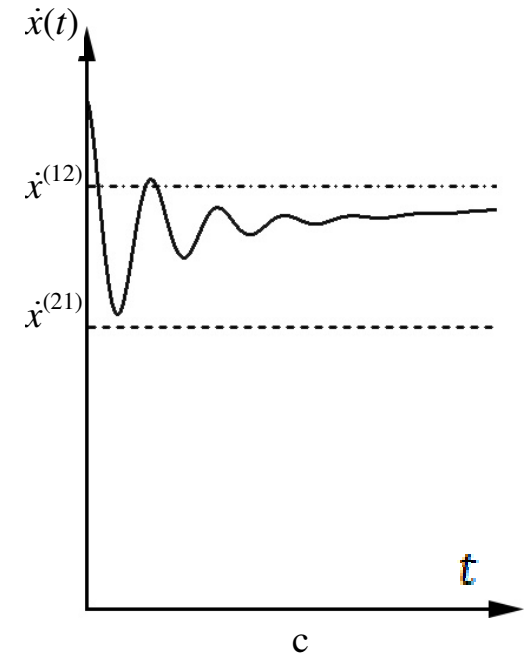

c

Fig. 4. Graphs of high-frequency oscillating shifts in automatic transmission at various gearshifting velocities magnitudes

As it can be seen in Figure 4a, the model enters the self-oscillation regime even under zero initial conditions. That is, the oscillations are self-excited, when the shifting speed is reached, while the amplitude of the oscillations from shift to shift increases.

There is a probability of reverse gearshift decreasing with increasing the difference between the velocities of neighbouring gears, as shown in Figures $4 b$ and $4 c$.

\section{Conclusions}

A mathematical model with elastic and dissipative elements is proposed for the dynamic analysis of the gearshifting processes in automatic transmissions and modelling of self-oscillations of the 
output shaft of the gearbox. Shifting gears is analysed as the impact interaction of transmission elements. The model allows for any modes of the vehicle motion to determine the conditions for occurrence of oscillating gearshifts and to develop criteria for minimizing this phenomenon.

The model can be used in the development of gearshifting control systems for automatic transmissions and calibration the engine operation modes and transmission under various conditions of vehicle movement.

\section{References}

[1] Саламандра К.Б. Современные методы синтеза автоматических планетарных коробок передач (Modern methods of synthesis of automatic planetary gearboxes). Izvestia MGTU "MAMI", 2017, No 3(33), pp. 49-55. (In Russian).

[2] Genta G., Morello L. The Automotive Chassis. Mechanical Engineering Series. Dordrecht: Springer, 2009. $627 \mathrm{p}$.

[3] Naunheimer H., Bertsche B., Ryborz J. etc. Automotive Transmissions. Berlin, Heidelberg: Springer, 2011.715 p.

[4] Bai Sh., Maguire J., Peng H. Dynamic analysis and control system design of automatic transmission. Warrendale, Pennsylvania, USA: SAE International, 2013. 205 p.

[5] Fischer R., Küçükay F., Jürgens G., Najork R., Pollak B. The Automotive Transmission Book. Powertrain. Cham: Springer, 2015. 355 p.

[6] Держанский В.Б., Тараторкин И.А. Адаптивное управление переключением передач гидромеханической трансмиссии на основе мониторинга технического состояния и режимов функционирования (Adaptive control of gear shifting of hydromechanical transmission based on monitoring of technical condition and operation modes). Vestnik of South Ural State University: Seriya mashinostroenine, 2005, No 14(54), pp. 75-84. (In Russian).

[7] Держанский В.Б., Тараторкин И.А., Рылеев А.В., Бураков Е.А. Прогнозирование цикличности переключения передач трансмиссии гусеничных машин (Forecasting the cyclicity of gearshift in transmission of caterpillar vehicles). Vestnik of South Ural State University: Seriya mashinostroenine, 2007, No 25(97), pp. 66-69. (In Russian).

[8] Васильев В.В. Анализ результатов теоретических и экспериментальных исследований алгоритмов управления автоматическими трансмиссиями колёсных машин (Analysis of the results of theoretical and experimental studies of control algorithms for automatic transmissions of wheeled vehicles). Jurnal avtomobilnikh injenerov, 2017, No 1(102), pp. 12-19. (In Russian).

[9] Шарипов В.М., Дмитриев М.И., Зенин А.С., Маланин И.А., Смирнов И.А. К вопросу о буксовании фрикционных сцеплений при переключении передач без разрыва потока мощности в коробках передач автомобилей и тракторов (On the slipping of friction clutches during gear shifting without interruption of power flow in gearboxes of cars and tractors). Traktori i selkhozmashini, 2015, No 6, pp. 5-9. (In Russian).

[10]Pfeiffer F. Mechanical System Dynamics. Corrected Second Printing. Berlin Heidelberg: Springer-Verlag, 2008. 575 p.

[11]Шарипов В.М., Дмитриев М.И., Зенин А.С., Савкин Я.В. Работа сцепления в коробке передач при переключении без разрыва потока мощности от двигателя (Work of Clutch Slipping in the Gearbox During Gear Shifting Without Breaking the Flow of Power From the Engine). Spravochnik. Injenerniy jurnal, 2010, No 11, pp. 8-15. (In Russian).

[12] Чудаков Е.А. Конструкция и расчет автомобиля. Третье исправленное и дополненное издание (Construction and calculation of the automobile. Third Corrected and Amended Edition). Moscow: MASHGIZ, 1953. 432 p. (In Russian).

[13] Salamandra, K.B.; Tyves, L.I. Integral Principle in the Problems of Dynamic Analysis of Gearshift in Automatic Gearboxes. Journal of Machinery Manufacture and Reliability, vol. 46, No. 5, 2017, pp. 434-441.

[14] Timoshenko S. Vibration problems in engineering. Second Edition. New York: D. Van Nostrand Company Inc., 1937. $470 \mathrm{p}$.

[15]Пановко Я.Г. Введение в теорию механических колебаний: Учеб. пособие для вузов. - 3-е изд., перераб. (Introduction to the theory of mechanical oscillations: Textbook manual for universities. Third edition). Moscow: Nauka, 1991. 256 p. (In Russian). 
[16] Вульфсон И.И. Динамические расчеты цикловых механизмов (Dynamic calculations of cyclic mechanisms). Leningrad: Mashinostroenie, 1976. 328 p. (In Russian).

[17]Вейц В.Л., Коловский М.З., Кочура А.Е. Динамика управляемых машинных агрегатов (Dynamics of controlled machine aggregates). Moscow: Nauka, 1984. 352 p. (In Russian).

[18] Babitsky V.I. Theory of Vibro-Impact Systems and Applications. Berlin, Heidelberg: Springer, 1998. $330 \mathrm{p}$.

[19] Babitsky V.I., Krupenin V.L. Vibration of Strongly Nonlinear Discontinuous Systems. Foundations of Engineering Mechanics. Berlin, Heidelberg: Springer, 2001. 404 p.

[20]Блохин А.Н. Моделирование процесса управления сцеплением многоступенчатой трансмиссии с пневмоприводом (Modeling of clutch control process of multistage transmission with gas). Aktualnie voprosi mashinovedeniya, 2014, vol. 3, pp. 139-143. (In Russian). 